\title{
Using occupancy analysis to validate the use of footprint tunnels as a method for monitoring the hedgehog Erinaceus europaeus
}

Article

Accepted Version

Yarnell, R., Pacheco, M., Williams, B., Neumann, J., Rymer, D. and Baker, P. (2014) Using occupancy analysis to validate the use of footprint tunnels as a method for monitoring the hedgehog Erinaceus europaeus. Mammal Review, 44 (3-4). pp. 234-238. ISSN 1365-2907 doi:

https://doi.org/10.1111/mam.12026 Available at https://centaur.reading.ac.uk/87581/

It is advisable to refer to the publisher's version if you intend to cite from the work. See Guidance on citing.

Published version at: https://onlinelibrary.wiley.com/doi/abs/10.1111/mam.12026

To link to this article DOI: http://dx.doi.org/10.1111/mam.12026

Publisher: Wiley

All outputs in CentAUR are protected by Intellectual Property Rights law, including copyright law. Copyright and IPR is retained by the creators or other copyright holders. Terms and conditions for use of this material are defined in the End User Agreement. 


\section{www.reading.ac.uk/centaur}

\section{CentAUR}

Central Archive at the University of Reading

Reading's research outputs online 


\title{
Using occupancy analysis to validate the use of footprint tunnels as a method for monitoring the hedgehog Erinaceus europaeus
}

\author{
Richard W. YARNELL* School of Animal, Rural and Environmental Sciences, Nottingham Trent \\ University, Brackenhurst, Southwell, Nottinghamshire NG25 OQF, UK. E-mail: \\ richard.yarnell@ntu.ac.uk
}

Marina PACHECO The Mammal Society, 3 The Carronades, New Road, Southampton SO14 OAA, UK.E-mail: marina.pacheco@themammalsociety.org

Ben WILLIAMS School of Biological Sciences, University of Reading, Whiteknights, Reading Berkshire RG6 6AS, UK. E-mail: b.williams@pgr.reading.ac.uk

Jessica L. NEUMANN School of Biological Sciences, University of Reading, Whiteknights, Reading Berkshire RG6 6AS, UK. E-mail: jess_n1@hotmail.co.uk

David J. RYMER School of Biological Sciences, University of Reading, Whiteknights, Reading Berkshire RG6 6AS, UK. E-mail:d.j.rymer@ reading.ac.uk

Philip J. BAKER School of Biological Sciences, University of Reading, Whiteknights, Reading Berkshire RG66AS, UK. E-mail:p.j.baker@reading.ac.uk

*Correspondence author

\begin{abstract}
Indirect survey methods are often used in studies of mammals, but are susceptible to biases caused by failure to detect species where they are present. Occupancy analysis is an analytical technique which enables non-detection rates to be estimated and which can be used to develop and refine novel survey methods. In this study, we investigated the use of footprint tunnels by volunteers as a method for surveying occupancy of sites by hedgehogs Erinaceus europaeus. The survey protocol led to a very low non-detection rate and could reasonably be used to detect occupancy changes of $25 \%$ with statistical power of 0.95 in a national survey.
\end{abstract}

\section{INTRODUCTION}

Accurate estimates of population size, or reliable surrogate measures, are essential for effective wildlife management and conservation. However, as many mammal species are difficult to observe directly, indirect techniques based upon field signs have been widely used (Wilson \& Delahay 2001). Yet indirect methods can be associated with significant problems (e.g. a lack of evidence that they correlate with animal density, failing to detect a species when it is present), which can lead to erroneous conclusions and inappropriate management actions. 
One approach for overcoming the problem of non-detection is the use of occupancy analysis, a maximum-likelihood based method in which repeated surveys are used to generate site-specific detection records from which the non-detection error rate can be estimated (MacKenzie et al. 2006). The application of occupancy analysis enables novel survey methods to be developed and refined so that error rates are minimised. We describe the use of footprint tunnels (Huijser \& Bergers 2000) in combination with occupancy analysis as a method for surveying western European hedgehogs Erinaceus europaeus, a species of conservation concern in the UK (Battersby 2005, Wembridge 2011).

\section{METHODS}

One hundred and eleven sites throughout the UK (but mostly in southern England) were surveyed between April 2011 and September 2013 inclusive. Surveys were conducted by members of local mammal groups and by university students supervised by the authors. Sites (e.g. farms, golf courses) were selected, without prior knowledge of hedgehog status, that were within acceptable commuting distance for surveyors and to which landowners granted access. At each site, 10 footprint tunnels (Figure 1) were placed alongside linear features (hedgerows, fences), as hedgehogs frequently follow these when travelling (Hof et al. 2012); tunnels were placed $>100 \mathrm{~m}$ apart, with no more than two tunnels in the same field. Tunnels were checked on five consecutive mornings at each site: food bait (tinned sausages) was replaced if necessary. Footprint papers were replaced if they were damaged or if hedgehog or non-target animal footprints were recorded; all papers were returned to the authors for verification.

Data were analysed using PRESENCE v5.7 software (Hines 2006). Each night was treated as a repeat survey; sites were classified as occupied if hedgehog footprints had been recorded in any tunnel on any night. Tunnels were not considered independent, as individual hedgehogs could have visited more than one tunnel each night. Data were analysed annually and after pooling across all three years; only the most recent information was used. In initial analyses, models were based upon constant versus variable (survey-specific) daily detection rates; the latter were used to investigate whether hedgehogs habituated to the tunnels over time. The optimal model was selected using minimum Akaike's Information Criterion (AIC) values, and was used to estimate the number of survey nights required to determine absence at a site at 0.80 and 0.95 confidence levels (McArdle 1990).

The effects of three categories of covariates on occupancy were investigated using subsets of the data: (i) season (spring: April-May; summer: June-July; autumn: August-September; N=111 sites); (ii) habitat ( $\mathrm{N}=87$ ); and (iii) habitat and the presence or absence of badgers Meles meles 
$(\mathrm{N}=73)$. The season was included in order to allow survey timing to be optimized; both habitat and badger presence have been shown to influence hedgehog presence (Young et al. 2006, Hubert et al. 2011). Land cover types representing UK Biodiversity Action Plan Broad Habitats obtained from Land Cover 2007 vector data (Morton et al. 2011) were aggregated into five categories: urban, woodland, grasslands, arable and other. Habitat availability was quantified as the proportional area of each class within a circle with radius $500 \mathrm{~m}$ centred on the centre of each site; this radius was selected to encapsulate the likely home range size of hedgehogs in these sites. As sample sizes were moderate, individual occupancy models included a maximum of two habitat classes. Badgers were classed as present or absent from each site based on field signs, observations during nocturnal spotlight counts and conversations with landowners. As the data were often over-dispersed, adjustments were made to the variance inflation factor $(\hat{c})$ and models were ranked by quasi-AIC (QAIC) values (Anderson \& Burnham 2002). Models with $\Delta$ QAIC values $>2$ or which did not converge were excluded as having little or no support (Burnham \& Anderson 2002), except where models with constant and variable detection daily detection rates were compared; in this case, models with $\triangle$ QAIC values $>2$ were included for illustrative purposes.

The suitability of the survey protocol for future monitoring purposes was assessed by estimating the number of sites needed to detect $(\alpha=0.05)$ a change in occupancy between two surveys $(50 \%, 25 \%, 10 \%)$ with four different levels of repeat surveys per site $(2,3,4$ and 5 days) at a given level of power $(0.80,0.90,0.95)$. Estimates of occupancy and detection were derived from the 111 sites surveyed. Simulations were used to verify the performance of each study design; each scenario was run 5000 times and power was calculated as the proportion of simulations in which a significant difference was detected. All analyses were conducted using R code provided by Guillera-Arroita and Lahoz-Monfort (2012).

\section{RESULTS}

Occupancy models with a constant daily detection rate performed better than those with a variable daily detection rate (Table 1). All further analyses were, therefore, conducted using constant daily detection rate models.

Collectively, naïve occupancy (the proportion of sites where hedgehogs were detected at least once) was 0.387 ; the daily detection probability was 0.593 (Table 1). There was negligible difference in naïve occupancy and estimated occupancy (0.392); the number of survey replicates required to determine absence ranged up to 3.6 (Table 1). Therefore, a survey conducted over four days was sufficient to be confident that the absence of footprints at a site reflected a true absence of hedgehogs. 
Neither season (Table 2a) nor habitat (Table 2b) covariates alone improved model fit above that based solely on a constant daily detection rate. However, there was a significant negative relationship between badgers and hedgehogs (Table 2c): hedgehogs were twice as likely to be present at sites without badgers $[\Psi=0.506 \pm 0.095$ (mean \pm standard error)] than at sites where badgers were present $(\Psi=0.247 \pm 0.065)$.

Given the sample sizes typically achieved in surveys of mammals by volunteers in the UK (<1000; Battersby 2005), power analyses indicated that the survey protocol would be suitable for detecting changes in occupancy of sites by hedgehogs in the order of $25 \%$ (Table 3). Substantially larger sample sizes would be required to detect changes of smaller magnitudes.

\section{DISCUSSION}

As hedgehog populations in Britain may be declining rapidly (Wembridge 2011), there is an urgent need for a method that can be used to monitor changes in hedgehog abundance and distribution, and to identify factors associated with their decline. The method should overcome some of the limitations associated with other methods currently being used (Battersby 2005, Hof \& Bright 2009, Roos et al. 2012), such as low detection rates (Poulton \& Reeve 2010), the non-random selection of sites (Toms $\&$ Newson 2006), and bias due to road avoidance by hedgehogs (Rondinini \& Doncaster 2002). The footprint tunnel method described in this study meets this need. Most importantly, naïve versus estimated occupancy rates were very similar, indicating a very small non-detection rate. These results provide strong evidence that the survey methodology reliably detected hedgehogs at sites where they were present. In addition, footprint tunnels can be used in a wide range of habitats and at a spatial scale that is likely to reflect different management practices within the wider landscape (e.g. on individual farms). They are also suitable for use by volunteer surveyors: tunnels can be placed optimally within each site in known positions, thereby eliminating the need to search for potentially sparse field signs; they can be checked during the day; and the resultant footprints can be retained for verification. Furthermore, lack of a seasonal effect between April and September on detection success, and the potential for reducing the amount of survey time required from five days to four further increase the technique's utility. The use of volunteers is likely to reduce costs significantly while simultaneously increasing statistical power and engaging stakeholders (Battersby 2005; Toms \& Newson 2006).

Although most sites surveyed were in southern England, the overall occupancy rate recorded in this study was similar to or lower than indices reported in other studies (36-45\% in urban areas, $30 \%$ on farms, 47-57\% of roads surveyed: Hof \& Bright 2009; Roos et al. 2012). Collectively, these data indicate that hedgehogs appear to be more heterogeneously distributed than they were 
historically. Similarly, acknowledging the limited sample size, only the presence or absence of badgers significantly affected hedgehog occupancy: this is consistent with other studies which have indicated a negative relationship between the two species (Young et al. 2006; Hubert et al. 2011; Hof et al. 2012). Assuming similar sample sizes to those achieved in other surveys of mammals by volunteers in the UK (Battersby 2005), our technique is appropriate for detecting c. 25\% changes in hedgehog occupancy with a high degree of statistical power.

In summary, we have field-tested an indirect survey method for hedgehogs using the framework of occupancy analysis to address the specific problem of non-detection. This represents a powerful approach for validating indirect methods in surveys of mammals.

\section{ACKNOWLEDGEMENTS}

We thank Ian Stephens for designing the footprint tunnel, Gurutzeta Guillera-Aroita for advice on power analysis and all students and volunteers who conducted surveys. The study was funded by The People's Trust for Endangered Species and the British Hedgehog Preservation Society and conducted in accordance with UK legislative requirements.

\section{REFERENCES}

Anderson DR, Burnham KP (2002) Avoiding pitfalls when using information-theoretic methods. Journal of Wildlife Management 66: 912-918.

Battersby J (2005) UK Mammals: Species Status and Population Trends. First Report by the Tracking Mammals Partnership. Joint Nature Conservation Committee /Tracking Mammals Partnership, Peterborough, UK.

Burnham KP, Anderson DR (2002) Model Selection and Multi-model Inference. Springer, Berlin, Germany.

Guillera-Arroita G, Lahoz-Monfort, JJ (2012). Designing studies to detect differences in species occupancy: power analysis under imperfect detection. Methods in Ecology and Evolution 3: 860-869.

Hines JE (2006) PRESENCE 5.3 - Software to estimate patch occupancy and related parameters. USGS-PWRC. Available at: www.mbr-pwrc.usgs.gov/software/presence

Hof AR, Bright PW (2009) The value of green-spaces in built-up areas for western hedgehogs. Lutra 52: 69-82.

Hof AR, Snellenberg J, Bright PW (2012) Food or fear? Predation risk mediates edge refuging in an insectivorous mammal. Animal Behaviour 83: 1099-1106.

Hubert P, Julliard R, Biagianti S, Poulle M-L (2011) Ecological factors driving the higher hedgehog (Erinaceus europaeus) density in an urban area compared to the adjacent rural area. Landscape and Urban Planning 103: 34-43.

Huijser MP, Bergers PJM (2000) The effects of roads and traffic on hedgehog (Erinaceus europaeus) populations. Biological Conservation 95: 111-116.

McArdle BH (1990) When are rare species not there? Oikos 57: 276-277.

MacKenzie D, Nichols JD, Royle JA, Pollock KH, Bailey LL, Hines JE (2006) Occupancy Estimation and Modelling: Inferring Patterns and Dynamics of Species Occurrence. Academic Press, London, UK. 
Morton D, Rowland C, Wood C, Meek L, Marston C, Smith G, Wadsworth R, Simpson IC (2011) Final Report for LCM2007 - the New UK Land Cover Map. Countryside Survey Technical Report No 11/07 NERC/Centre for Ecology \& Hydrology, UK.

Poulton SMC, Reeve NJ (2009) A Pilot Study of a Method to Monitor Hedgehogs (Erinaceus europaeus). Unpublished report, The Mammal Society, Southampton, UK.

Rondinini C, Doncaster CP (2002) Roads as barriers to movement for hedgehogs. Functional Ecology 16: 504-509.

Roos S, Johnston A, Noble D (2012) UK Hedgehog Datasets and Their Potential for Long-term Monitoring. BTO Research Report No. 598, British Trust for Ornithology, Thetford, Norfolk, UK.

Toms MP, Newson SE (2006) Volunteer surveys as a means of inferring trends in garden mammal populations. Mammal Review 36: 309-317.

Wembridge D (2011) The State of Britain's Hedgehogs. People's Trust for Endangered Species, London. http://www.ptes.org/files/1428_sobh2011lowres.pdf

Wilson GJ, Delahay RJ (2001) A review of methods to estimate the abundance of terrestrial carnivores using field signs and observation. Wildlife Research 28: 151-164.

Young RP, Davison J, Trewby ID, Wilson GJ, Delahay RJ, Doncaster CP (2006) Abundance of hedgehogs (Erinaceus europaeus) in relation to the density and abundance of badgers (Meles meles). Journal of Zoology 269: 349-356. 
Table 1. Summary of models to estimate the probability of occupancy ( $\Psi$, shown \pm standard error) of survey sites by hedgehogs, based upon constant ( 2 parameters) versus variable daily detection rates (6 parameters); estimated occupancy rates are given only for constant detection rate models. The number of surveys needed is the number of visits required on consecutive nights to be $80 \%$ and $95 \%$ confident that non-detection at a site reflects the true absence of hedgehogs. Since the number of surveys needed is derived from a sample estimate of detection, the confidence intervals around the number of sites needed were calculated from the standard errors derived from the detection estimates (McArdle 1990).

QAIC = Quasi-Akaike's Information Criterion

$\triangle \mathrm{QAIC}=$ Delta Quasi-Akaike's Information Criterion: the difference in QAIC value between each model and the current top-ranked model (that with the lowest QAIC).

AICwgt = Akaike's Information Criterion weight: a measure of support for each model being the 'best' model

$\mathrm{SE}=$ standard error

\begin{tabular}{|c|c|c|c|c|c|c|c|c|c|}
\hline \multirow[t]{2}{*}{ Year } & \multirow{2}{*}{$\begin{array}{l}\text { No. } \\
\text { of } \\
\text { sites }\end{array}$} & \multirow{2}{*}{$\begin{array}{l}\text { Daily } \\
\text { detection } \\
\text { rate }\end{array}$} & \multirow[t]{2}{*}{ QAIC } & \multirow[t]{2}{*}{$\Delta Q A I C$} & \multirow[t]{2}{*}{ AICwgt } & \multirow[t]{2}{*}{$\begin{array}{l}\text { Estimated } \\
\Psi( \pm \text { SE })\end{array}$} & \multirow[t]{2}{*}{$\begin{array}{l}\text { Detection } \\
\text { rate }( \pm \text { SE })\end{array}$} & \multicolumn{2}{|c|}{$\begin{array}{c}\text { No. of surveys needed } \\
( \pm 1.96 \mathrm{SE})\end{array}$} \\
\hline & & & & & & & & $\begin{array}{c}\mathbf{8 0 \%} \\
\text { confidence }\end{array}$ & $\begin{array}{c}95 \% \\
\text { confidence } \\
\end{array}$ \\
\hline \multirow[t]{2}{*}{2011} & \multirow[t]{2}{*}{26} & Constant & 55.11 & 0.00 & 0.937 & \multirow[t]{2}{*}{$0.385(0.095)$} & \multirow[t]{2}{*}{$0.820 \quad(0.055)$} & \multirow[t]{2}{*}{$1.0(0.6-1.4)$} & \multirow[t]{2}{*}{$1.7(1.1-2.5)$} \\
\hline & & Variable & 60.51 & 5.40 & 0.063 & & & & \\
\hline \multirow[t]{2}{*}{2012} & \multirow[t]{2}{*}{62} & Constant & 117.30 & 0.00 & 0.961 & \multirow[t]{2}{*}{$0.476(0.065)$} & \multirow[t]{2}{*}{$0.556 \quad(0.043)$} & \multirow[t]{2}{*}{$1.9(1.6-2.5)$} & \multirow[t]{2}{*}{$3.6(2.9-4.6)$} \\
\hline & & Variable & 123.68 & 6.38 & 0.039 & & & & \\
\hline \multirow[t]{2}{*}{2013} & \multirow[t]{2}{*}{32} & Constant & 92.33 & 0.00 & 0.971 & \multirow[t]{2}{*}{$0.315(0.083)$} & \multirow[t]{2}{*}{$0.615 \quad(0.071)$} & \multirow[t]{2}{*}{$1.7(1.2-2.5)$} & \multirow{2}{*}{$\begin{array}{l}3.1(2.2- \\
4.6)\end{array}$} \\
\hline & & Variable & 99.35 & 7.02 & 0.029 & & & & \\
\hline \multirow{2}{*}{$\begin{array}{l}\text { All } \\
\text { years }\end{array}$} & \multirow[t]{2}{*}{111} & Constant & 159.95 & 0.00 & 0.944 & \multirow[t]{2}{*}{$0.392(0.047)$} & \multirow[t]{2}{*}{$0.593 \quad(0.035)$} & \multirow[t]{2}{*}{$1.8(1.5-2.2)$} & \multirow{2}{*}{$\begin{array}{l}3.3(2.8- \\
4.1)\end{array}$} \\
\hline & & Variable & 165.58 & 5.63 & 0.056 & & & & \\
\hline
\end{tabular}


Table 2. Summary of constant detection rate models comparing the effects of (a) season $(\mathrm{N}=111$ sites), (b) habitat composition only ( $\mathrm{N}=87$ sites) and (c) habitat composition and the presence or absence of badgers ( $\mathrm{N}=73$ sites) on occupancy of sites by hedgehogs. The model with badgers only best explains occupancy of sites by hedgehogs. Models with $\triangle$ QAIC values $>2$ were excluded.

QAIC = Quasi-Akaike's Information Criterion

$\triangle \mathrm{QAIC}=\operatorname{Delta}(\Delta)$ Quasi-Akaike's Information Criterion is the relative difference in QAIC values between each model and the currently top-ranked model (the one with smallest QAIC)

AICwgt $=$ is the Akaike's Information Criterion weight which is a measure of support for each model being the 'best' model

$\mathrm{SE}=$ standard error

\begin{tabular}{|l|l|l|c|c|c|c|}
\hline Analyses & Covariates & QAIC & $\Delta$ QAIC & AICwgt & $\begin{array}{c}\text { No. } \\
\text { parameters }\end{array}$ & $\begin{array}{c}-2 \text { log } \\
\text { likelihood }\end{array}$ \\
\hline (a) Season & - & 165.73 & 0.00 & 1.00 & 2 & 436.67 \\
\hline \multirow{4}{*}{ (b) Habitat } & - & 126.95 & 0.00 & 0.55 & 2 & 319.66 \\
\cline { 2 - 6 } & Arable & 128.70 & 1.75 & 0.23 & 3 & 319.01 \\
\cline { 2 - 6 } & Urban & 128.71 & 1.76 & 0.22 & 3 & 319.05 \\
\hline \multirow{2}{*}{$\begin{array}{l}\text { (c) Habitat } \\
\text { and badgers }\end{array}$} & Badgers & 112.91 & 0.00 & 0.36 & 3 & 256.59 \\
\cline { 2 - 7 } & - & 112.98 & 0.07 & 0.35 & 2 & 261.54 \\
\cline { 2 - 7 } & Arable and badgers & 114.60 & 1.69 & 0.15 & 4 & 255.83 \\
\cline { 2 - 7 } & Grass and badgers & 114.87 & 1.96 & 0.14 & 4 & 256.49 \\
\hline
\end{tabular}


Table 3. Results of power analysis showing the number of sites required to detect a significant percentage change in site occupancy by hedgehogs for a given survey effort, to achieve different levels of statistical power.

\begin{tabular}{|c|c|c|c|c|}
\hline \multirow[t]{2}{*}{$\begin{array}{l}\text { \% change in } \\
\text { occupancy }\end{array}$} & \multirow{2}{*}{$\begin{array}{c}\text { Survey effort } \\
\text { (no. of days } \\
\text { surveyed) }\end{array}$} & \multicolumn{3}{|c|}{$\begin{array}{l}\text { No. of sites required to achieve stated level of statistical } \\
\text { power }\end{array}$} \\
\hline & & 0.80 & 0.90 & 0.95 \\
\hline 10 & \multirow[t]{3}{*}{2} & 4250 & 5690 & 7036 \\
\hline 25 & & 640 & 856 & 1059 \\
\hline 50 & & 140 & 188 & 232 \\
\hline 10 & \multirow[t]{3}{*}{3} & 2820 & 3775 & 4668 \\
\hline 25 & & 429 & 574 & 710 \\
\hline 50 & & 95 & 127 & 157 \\
\hline 10 & \multirow[t]{3}{*}{4} & 2537 & 3396 & 4200 \\
\hline 25 & & 387 & 519 & 641 \\
\hline 50 & & 86 & 115 & 142 \\
\hline 10 & \multirow[t]{3}{*}{5} & 2453 & 3283 & 4060 \\
\hline 25 & & 375 & 502 & 621 \\
\hline 50 & & 84 & 112 & 138 \\
\hline
\end{tabular}


Figure 1. Design of the footprint tunnels used to survey hedgehogs in this study. Tunnels were constructed from corrugated plastic (Correx $\left.{ }^{\circledR}\right)$. Bait consisted of commercial hotdog sausages to attract hedgehogs into the tunnel and the ink was made of vegetable oil and carbon powder.

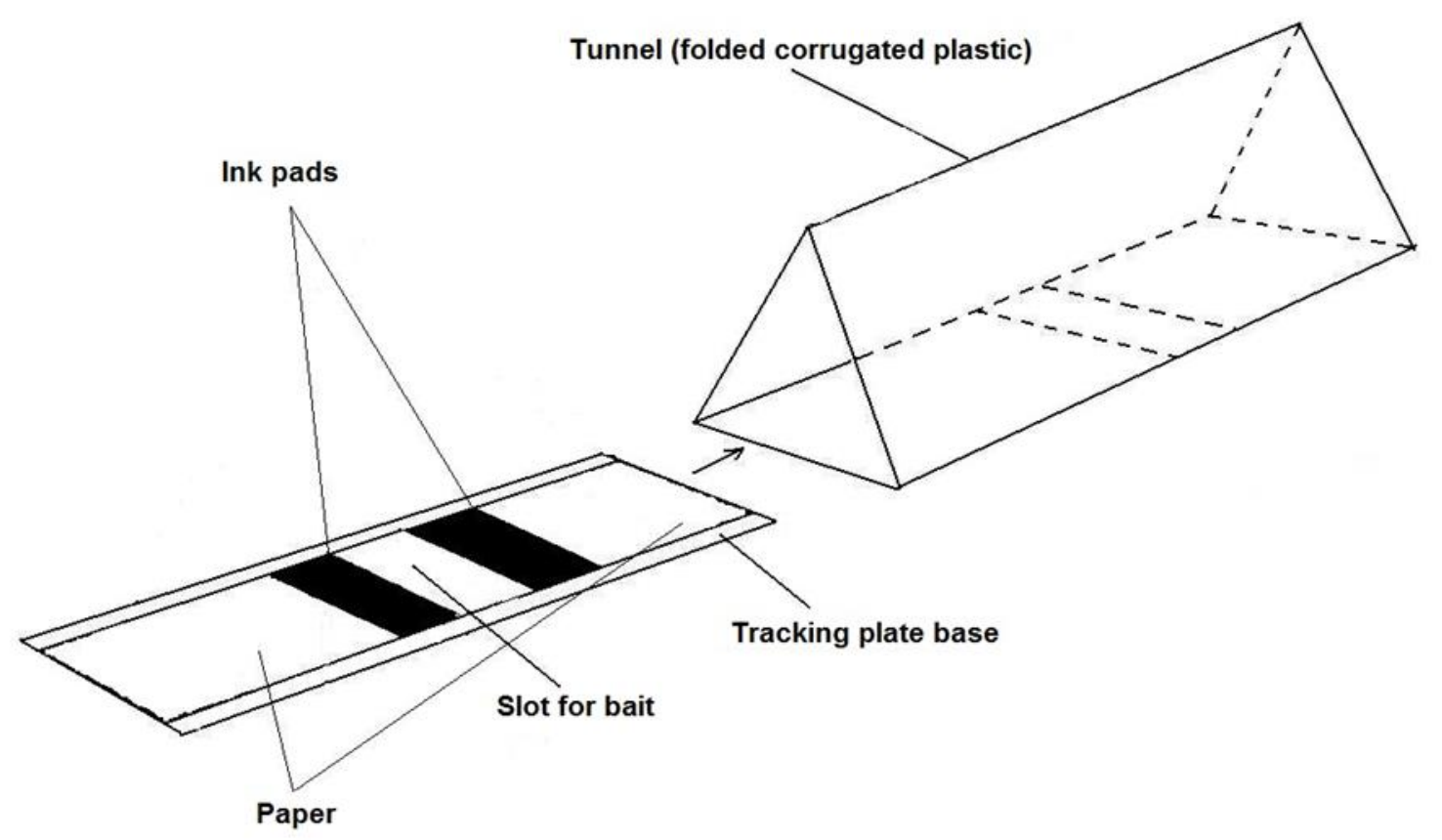

